
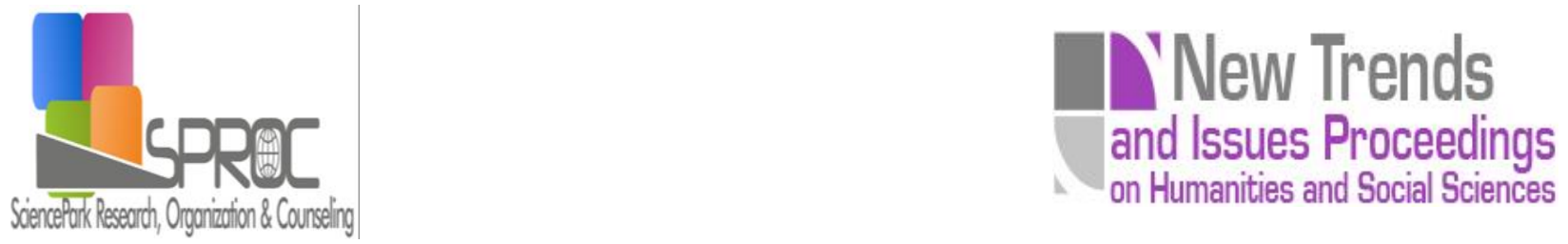

\title{
The Impact of the Educational Process to the Perception; Evaluation of the Urban Elements Relative to The Gestalt Theory
}

Demet Yilmaz Yildirim * Ayse Sagsoz , Alper Uzunali ${ }^{\mathrm{c}}$,

Suggested Citation:

$m \quad m \quad m$

.$M v \quad m \quad m$ $m f f t \quad m$

Abstract 
1. Introduction 
Figure/Ground

Principle of

ffth $m$ 
Experience:

Constancy:

Law of organization:

Proximity:

Similarity:

Comman fate;

Good continuity:

Closure:

2. Research 


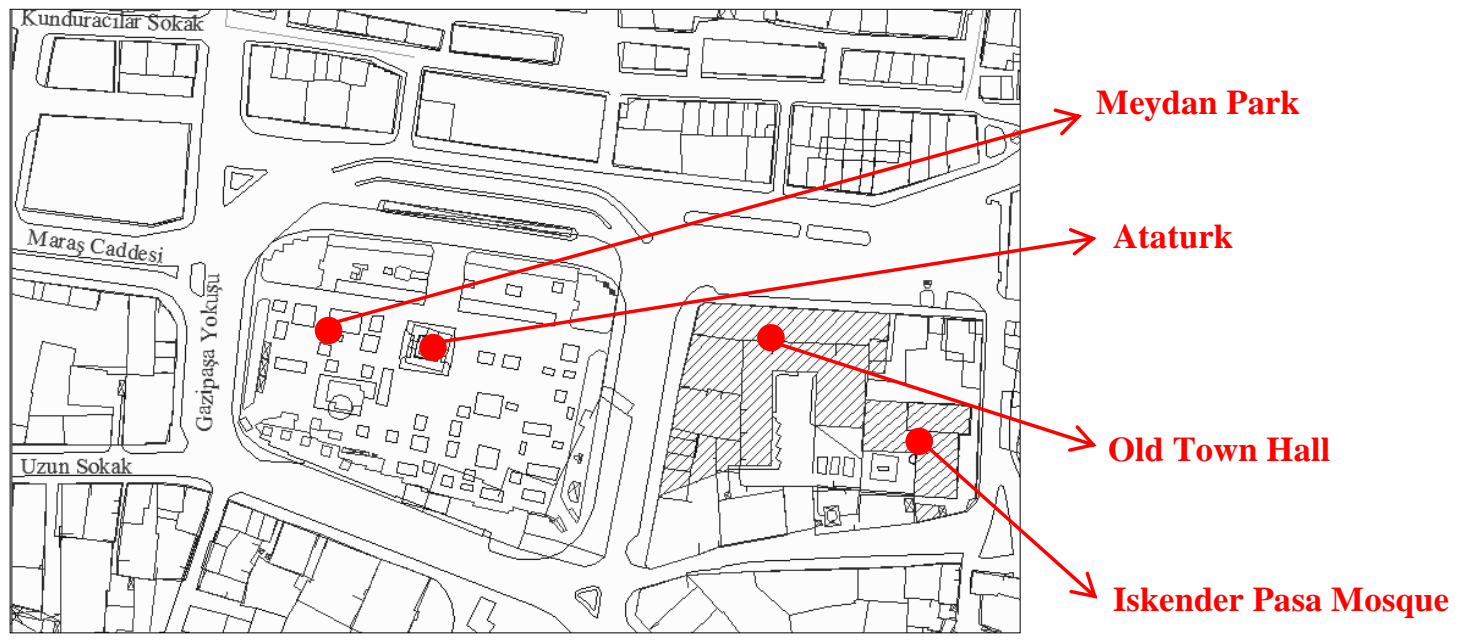

Figure 1. Location of Meydan Park and Ataturk Monument (the Archive of Trabzon Municipality)

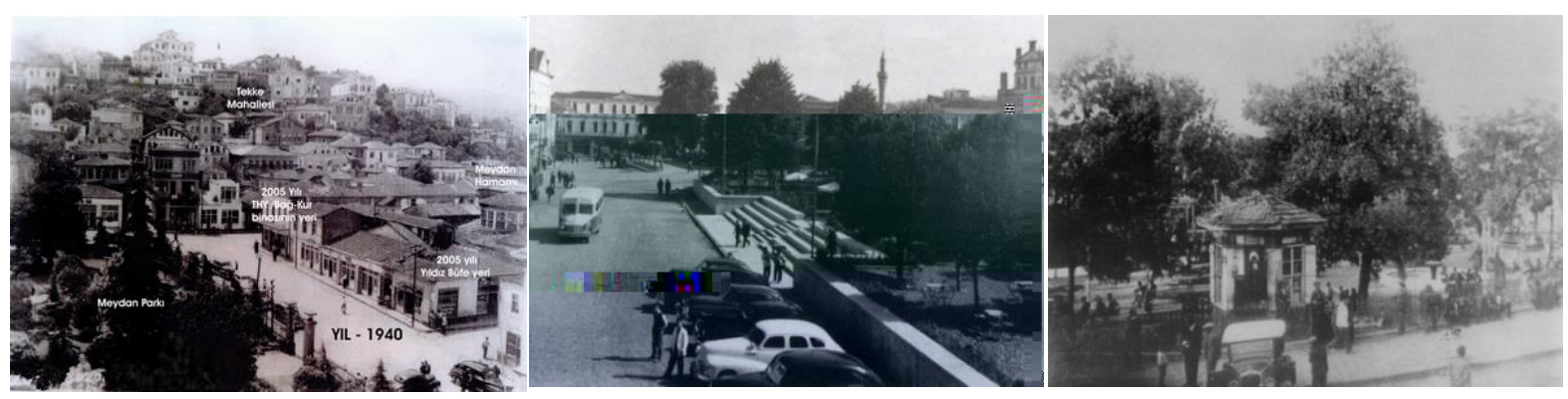

Figure 2. Old conditions of Meydan Park in 1940, 1925 ve 1950 (http://forum.bordomavi.net, http://www.koprubasi.net, http://www.trabzonum.net) 
$\begin{array}{llllllll}M v & m & m & m f f t & m & m & m & m\end{array}$
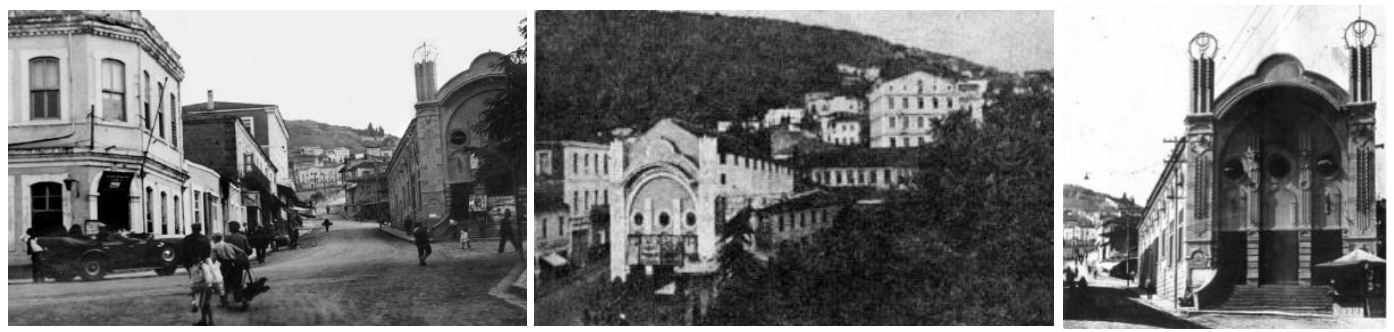

Figure 3. Old Town Hall, Sumer Cinema (Turan Cinema), Meydan Park (http://maviboncuk.blogspot.com.tr/2013/02/trabzon-opera-sumer-cinema.html
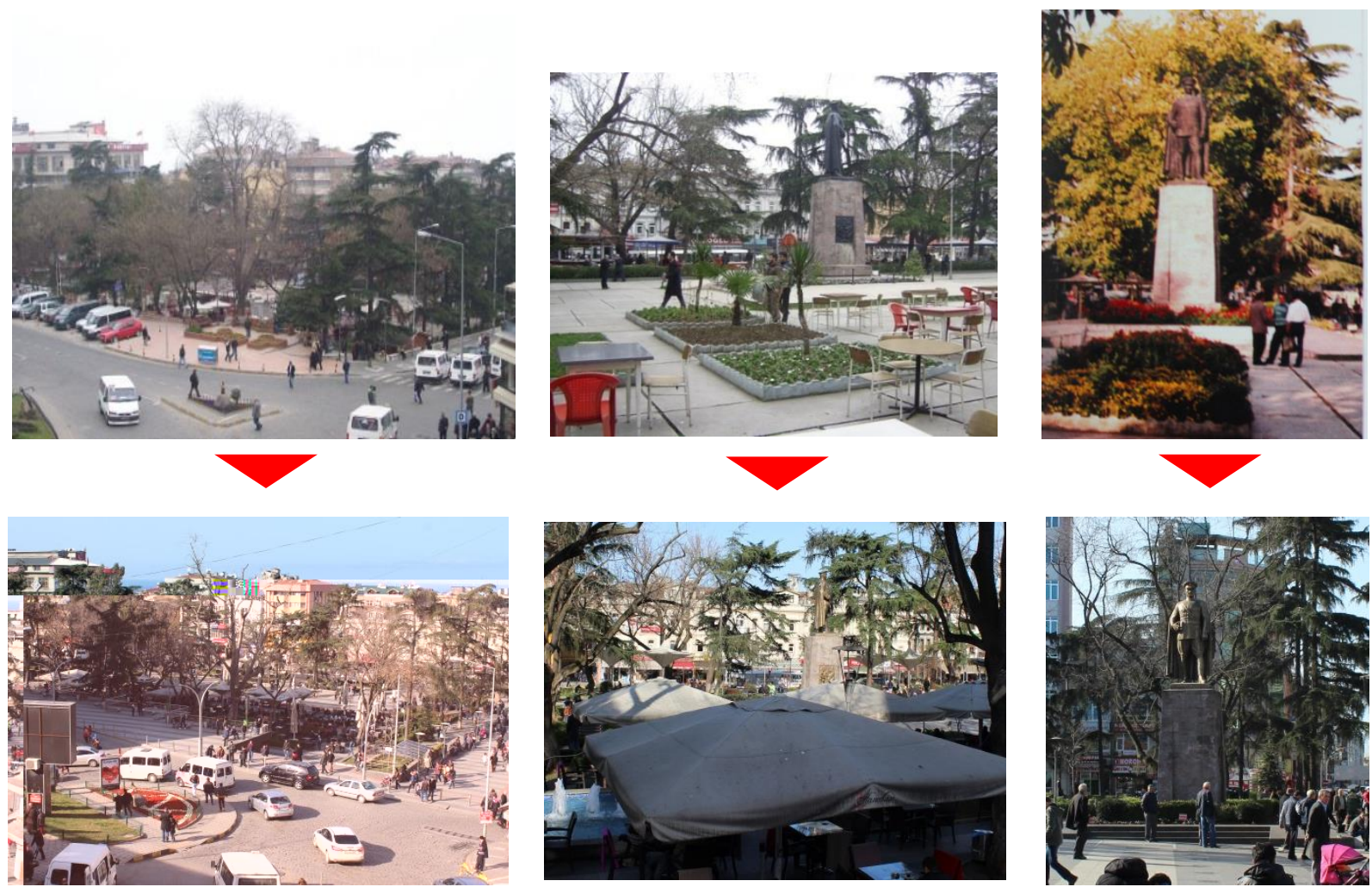

Figure 4. Before The Renovation of Meydan Park in 2008, After The Renovation of Square Park in 2013 (Archive of Yildirim Y. D.) 

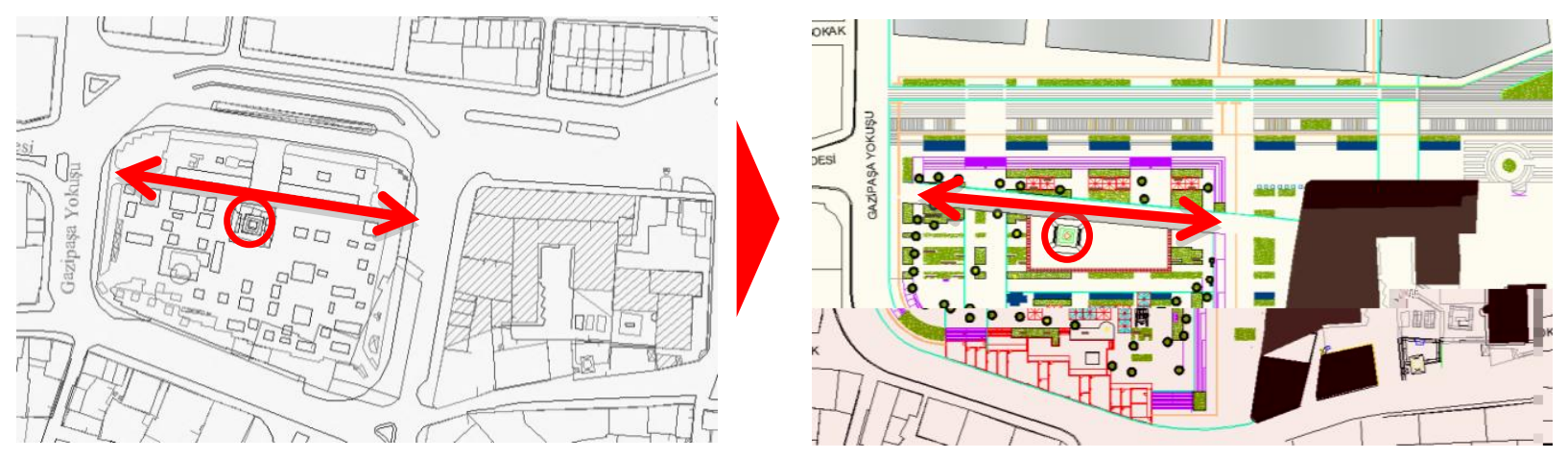

Figure 5. Location of Ataturk Monument Before And After The Renovation of Park (the Archive of Trabzon Municipality)

\subsection{Stages/Working Process and Method}

$$
n=\frac{\mathrm{Nx}(\mathrm{t})^{2} \mathrm{x}(\mathrm{p}) \mathrm{x}(\mathrm{q})}{(\mathrm{N}-1) \mathrm{x}(\mathrm{d})^{2}+(\mathrm{t})^{2} \mathrm{x}(\mathrm{p}) \mathrm{x}(\mathrm{q})} 40=\frac{252 \mathrm{x}(1,96)^{2} \mathrm{x}(0,8) \mathrm{x}(0,2)}{(252-1) \mathrm{x}(0,1)^{2}+(1,96)^{2} \mathrm{x}(0,8) \mathrm{x}(0,2)}
$$




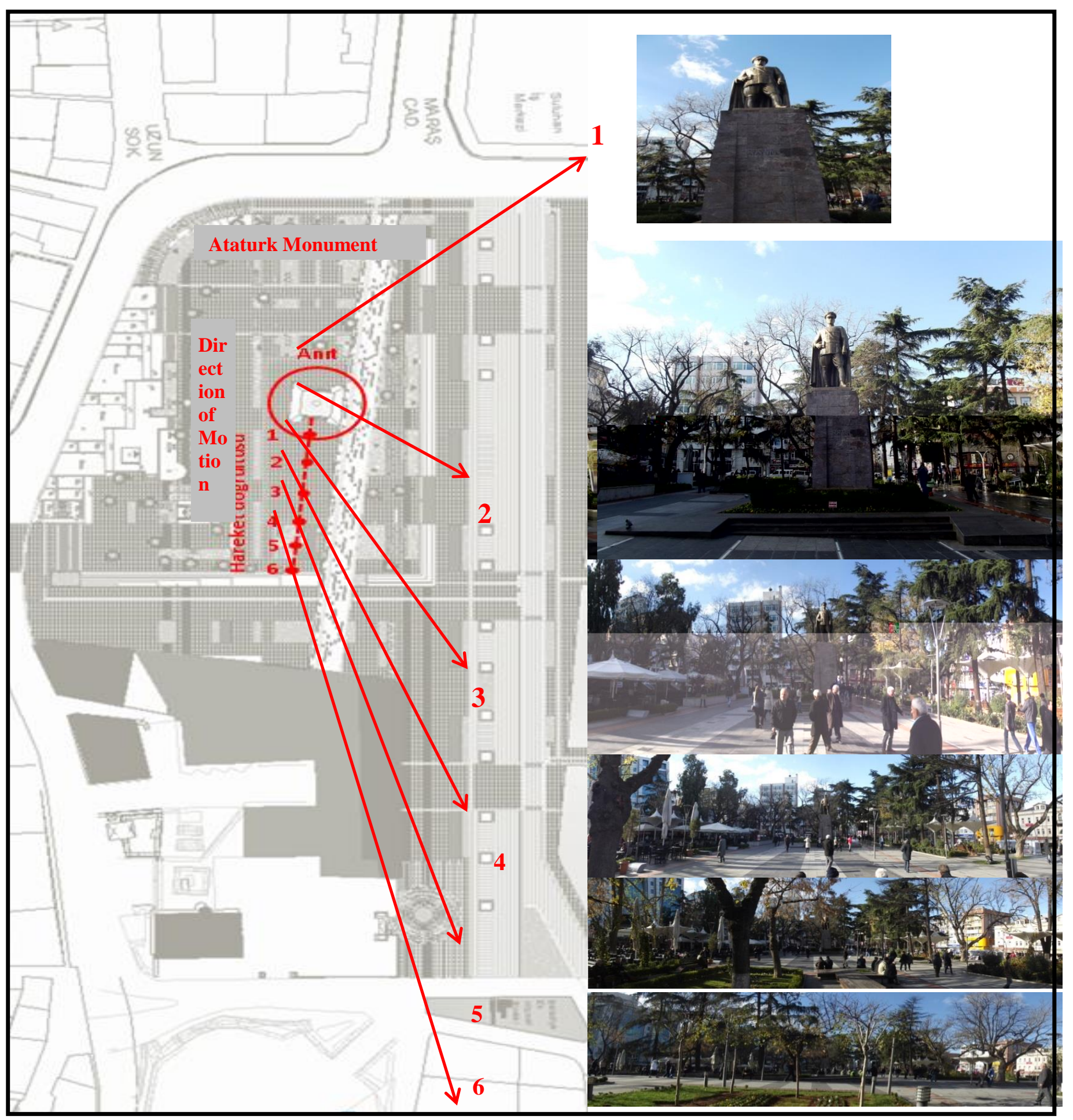

Figure 6. Photos and their locations 


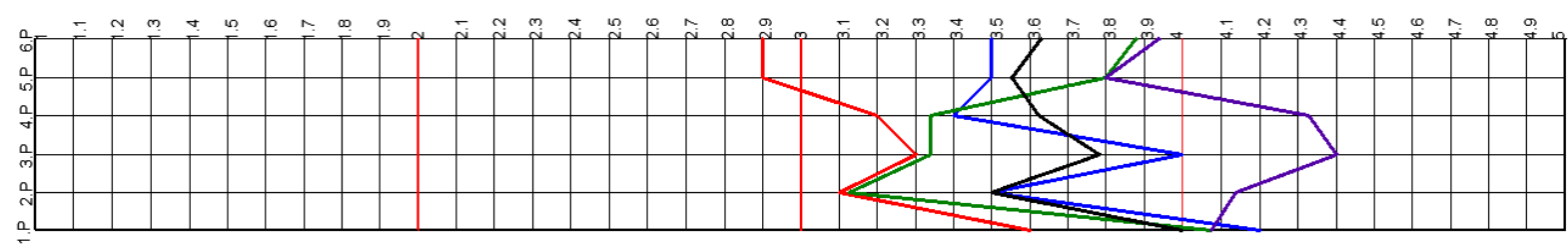
blue color: first grade , red color: second grade , green color:third grade, purple color:forth grade, black color: average of grades Figure7. Proximity principle according to the grades

$m$

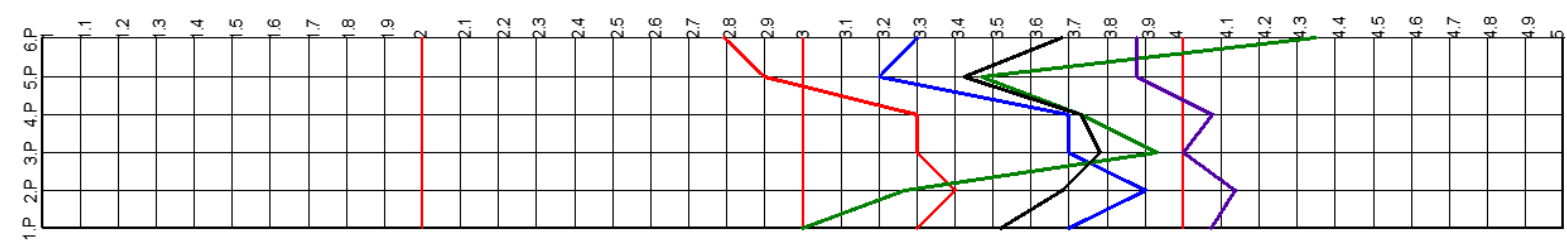
blue color: first grade , red color: second grade , green color:third grade, purple color:forth grade, black color: average of grades Figure 8.Similarity principle according to the grades 
$\begin{array}{llllllll}\text { M } & m & m & m f f t & m & m & m & m\end{array}$

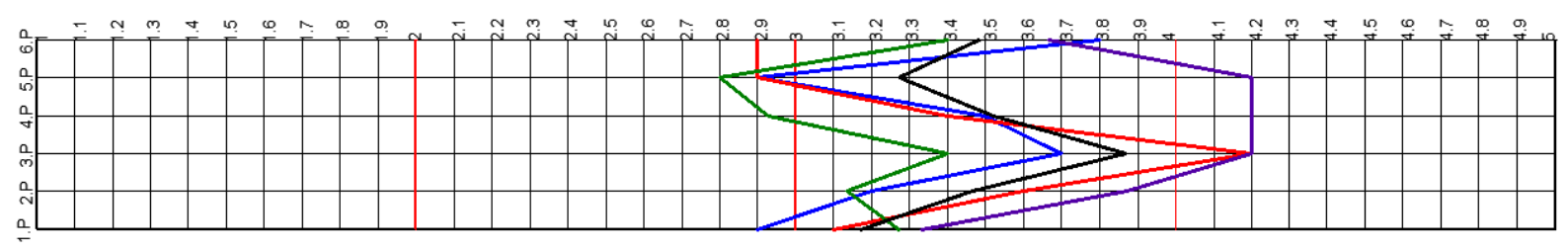

blue color: first grade , red color: second grade , green color:third grade , purple color:forth grade, black color: average of grades Figure 9. Closure principle according to the grades

$\bullet$

fft $\quad m m$

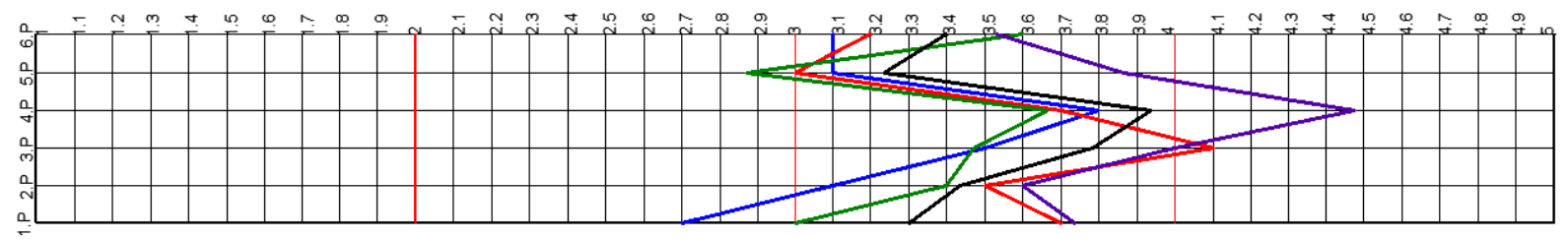

blue color: first grade , red color: second grade , green color:third grade, purple color:forth grade, black color: average of grades Figure 10. Good continuity principle according to the grades

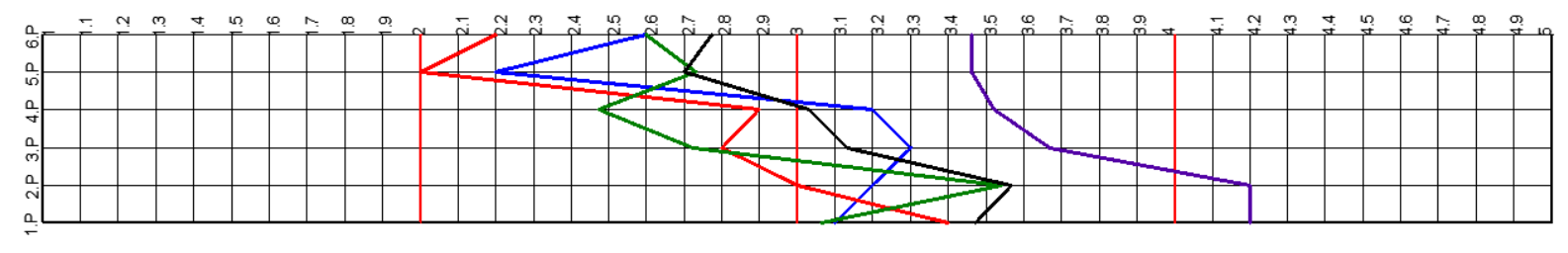

blue color: first grade , red color: second grade , green color:third grade, purple color:forth grade, black color: average of grades 


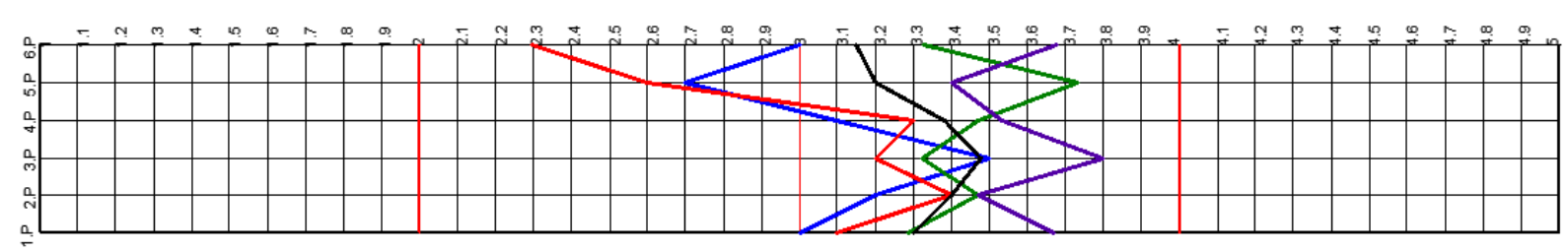

blue color: first grade, red color: second grade, green color:third grade, purple color:forth grade, black color: average of grades

Figure 12. Constancy principle according to the grades
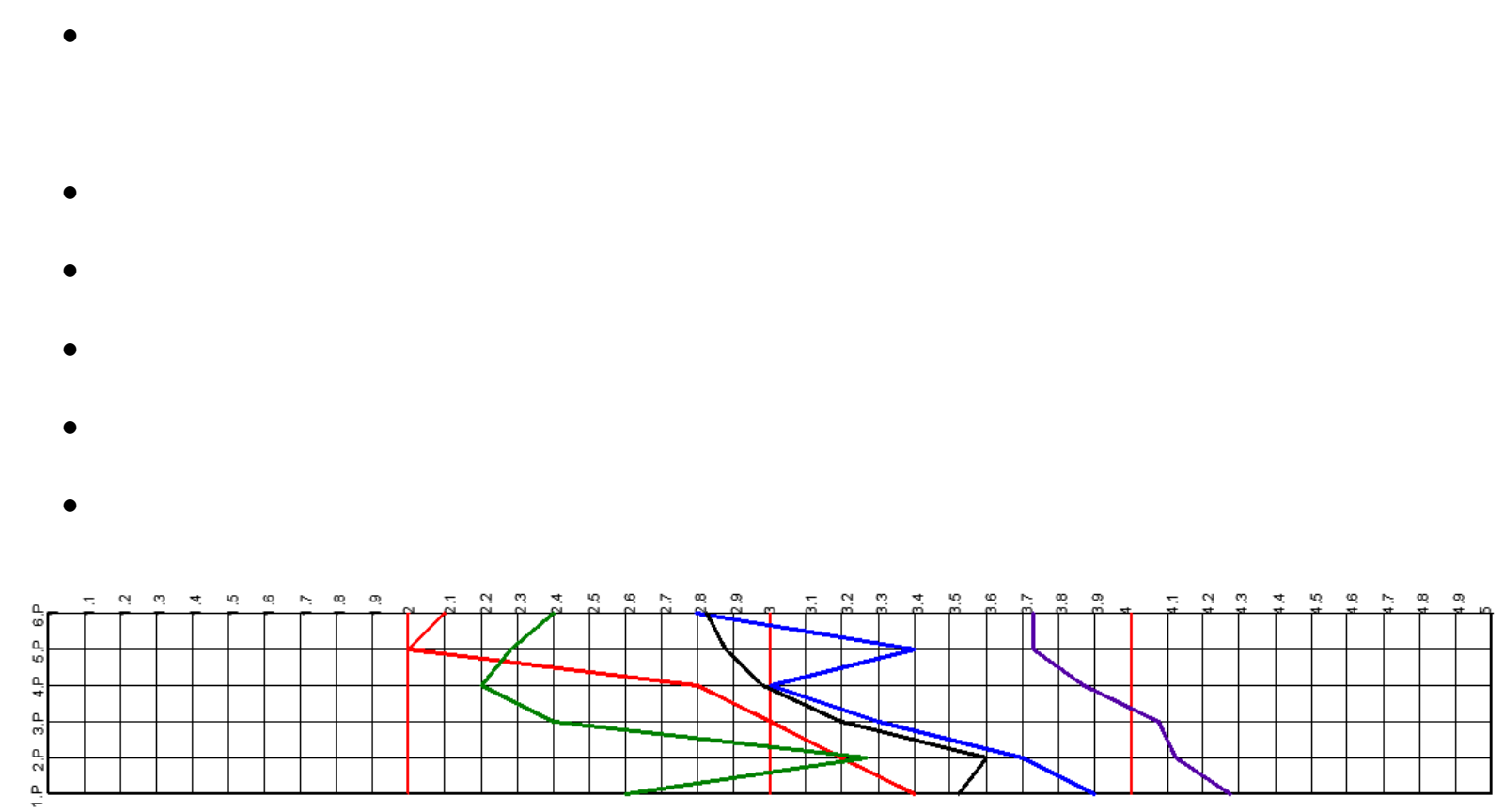

blue color: first grade, red color: second grade, green color:third grade, purple color:forth grade, black color: average of grades

Figure 13. Experience principle according to the grades
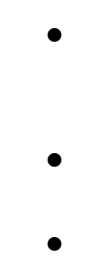

fft

fft

V

fft 
$\begin{array}{llllllll}\text { M } & m & m & m f f t & m & m & m & m\end{array}$

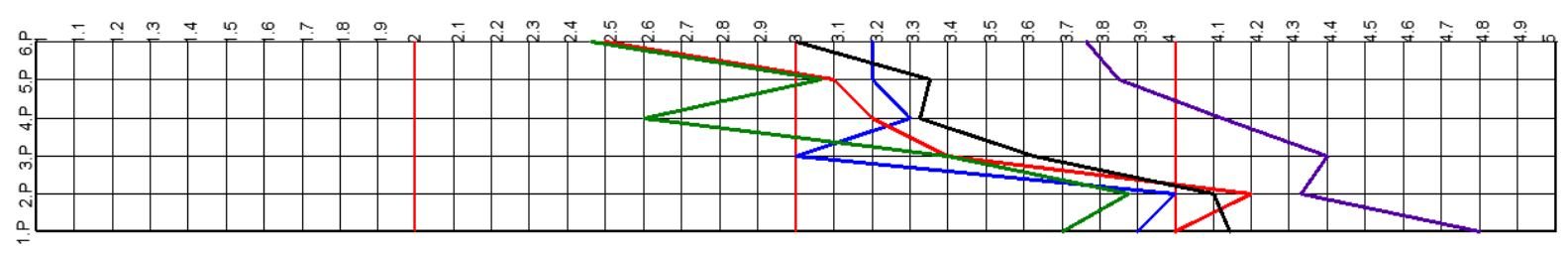

blue color: first grade , red color: second grade, green color:third grade, purple color:forth grade, black color: average of grades

Figure 14. Perceptibility principle according to the grades

\subsection{The Discussions}

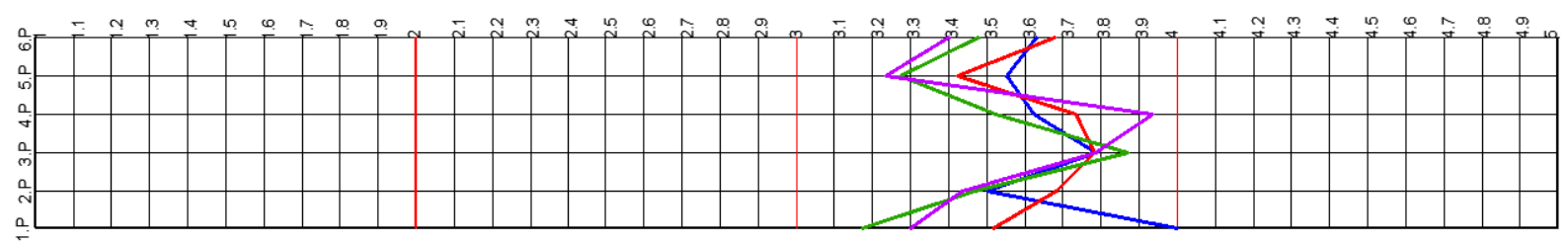

blue color: proximity, red color: similarity, green color: closure, purple color: good continuation

Figure 15. The changes of the proximity, similarity, closure and good continuation principles averages according to all grades

$$
\bullet
$$

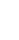


$\begin{array}{lllllll}M & m & m & m f f t & m & m & m\end{array}$

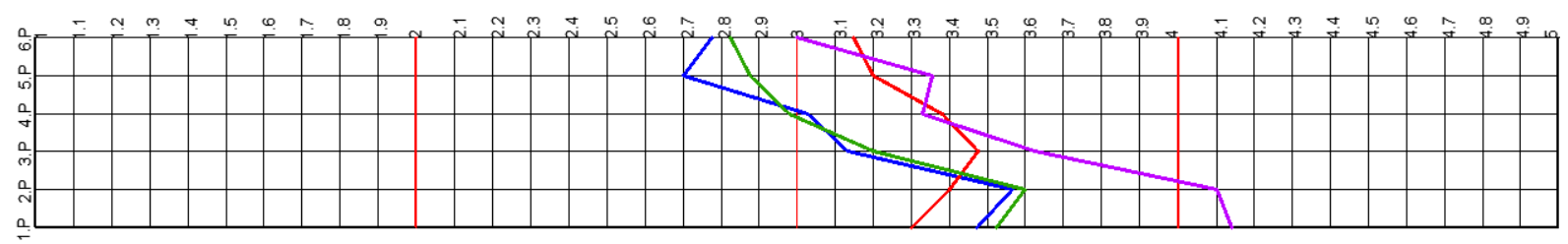

blue color: pragnanz, red color: constancy, green color: experience, purple color: perceptibility

Figure 16. The changes of the pragnanz, constancy, experience and perceptibility averages according to all grades
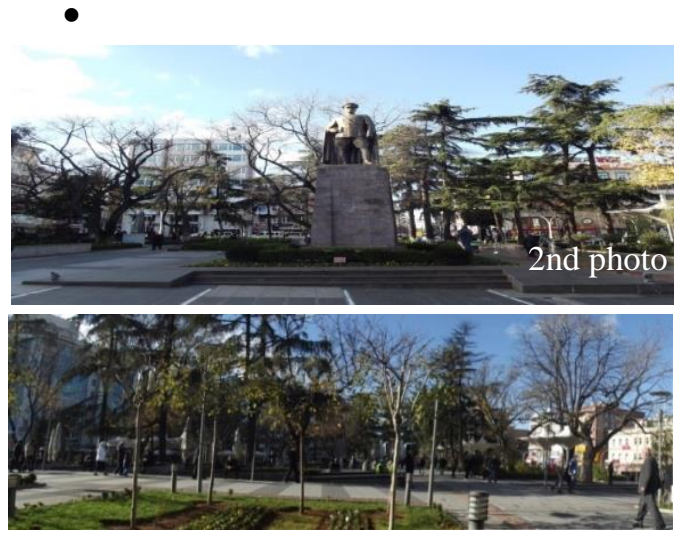

Figure 17. The perceptibility of photo

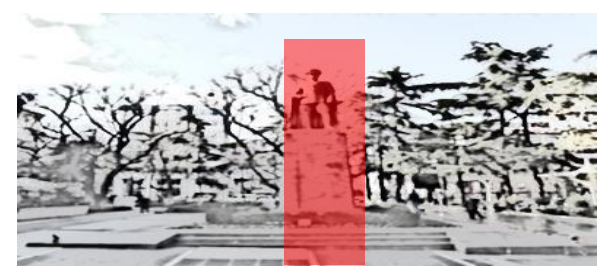

Figure 18. Figure-Ground Effect of photo
For 1st, 2nd and 3rd grades the perceptibility of the 2nd photo and for 4 th grade, the perceptibility of the 1st photo is the highest.

For 1st grade the perceptibility of the 5th and 6th photo for the other grades the perceptibility of 6 th photo is the lowest (Fig. 17).

\begin{tabular}{l|ll}
\hline Perceptibility & \multicolumn{1}{c}{ The highest } & The lowest \\
\hline & 2 photo & 5 ve 6 photo \\
1.grade & 2 photo & 6 photo \\
2.grade & 2 photo & 6 photo \\
3. grade & 1 photo & 6 photo \\
4. grade & .
\end{tabular}

According to the average of all grades the monument is the most perceived element in the second photo which has the highest perceptibility. So the monument is a

\begin{tabular}{lll}
\hline Figure & Ground \\
\hline monument & buildings \\
monument & buildings, tree \\
monument & - \\
monument & shade structure, \\
& & human \\
\hline
\end{tabular}


Table 1. Figure-ground relation according to the different grades

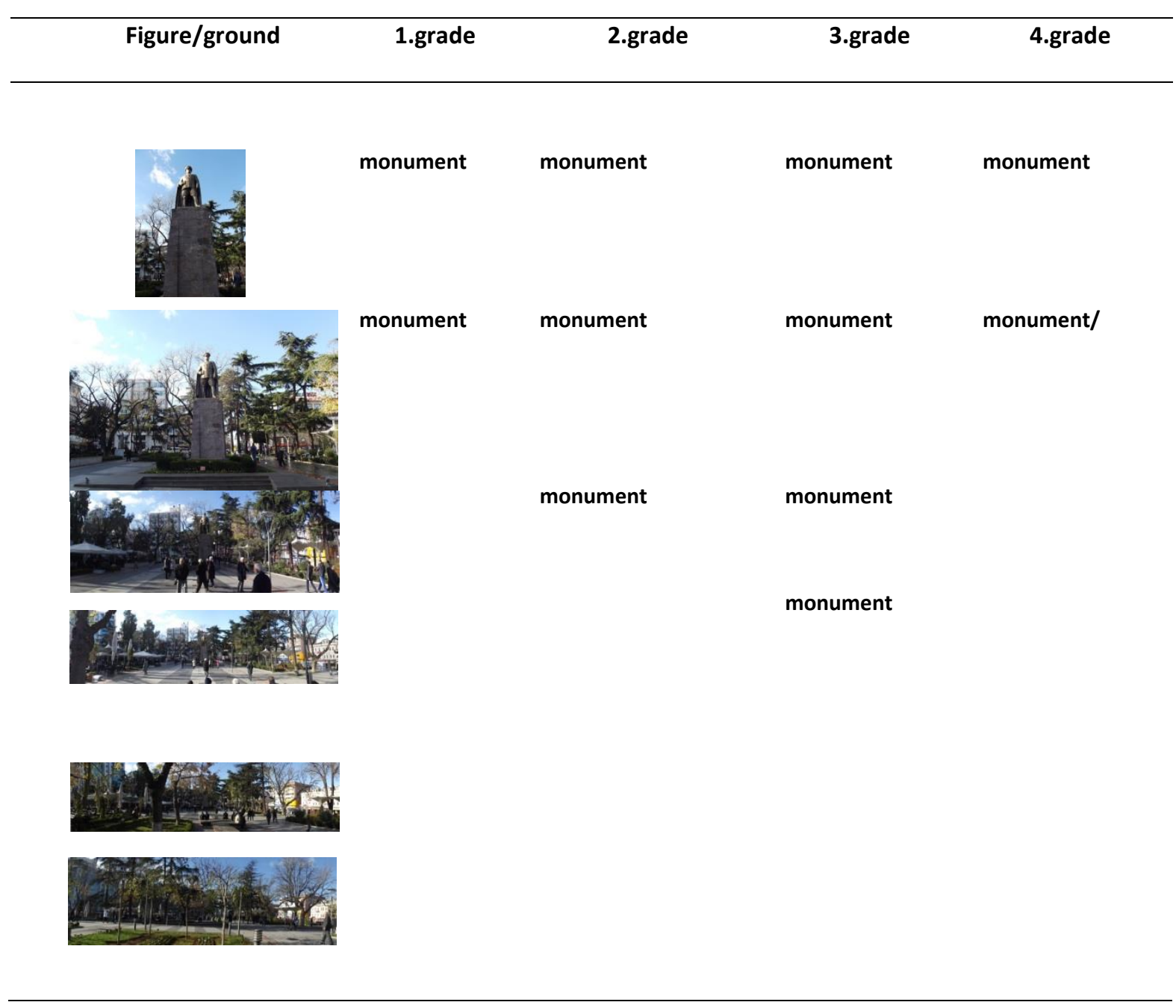

-
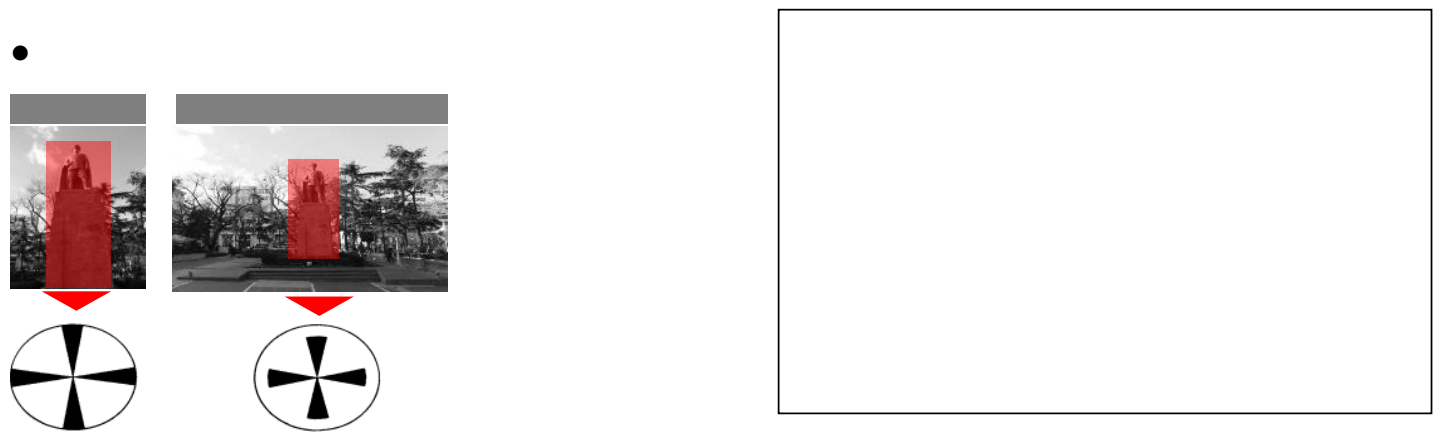
Table 3. Grades given the highest and lowest level to the Gestalt Principles in the second photo the highest and lowest level to the Gestalt Principles

\begin{tabular}{llllll}
\hline $\begin{array}{l}\text { proximit } \\
y\end{array}$ & similarity & closure & $\begin{array}{l}\text { Good } \\
\text { continuation }\end{array}$ & pragnanz constancy experiment perceptibility \\
\hline
\end{tabular}

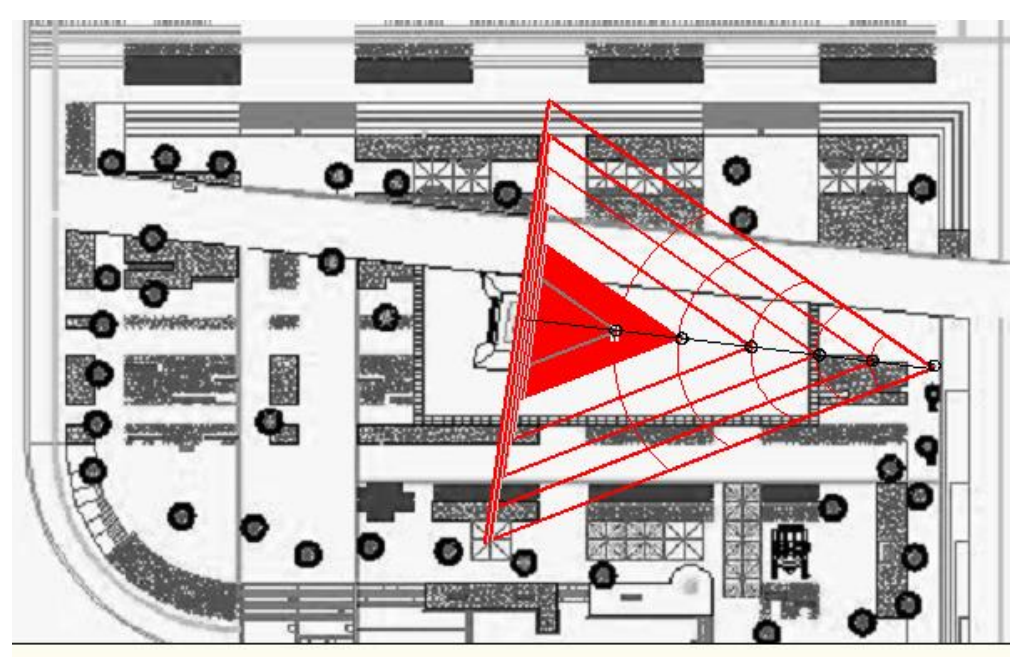

Figure 20. Changing sight according to horizontal movement 


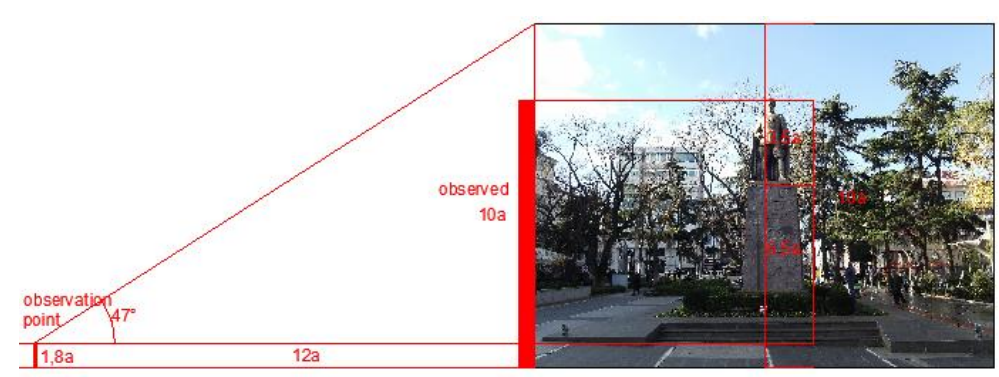

2.5. Conclusion

Figure 21. Viewpoint and vertical sight in the second photo 
References 
